
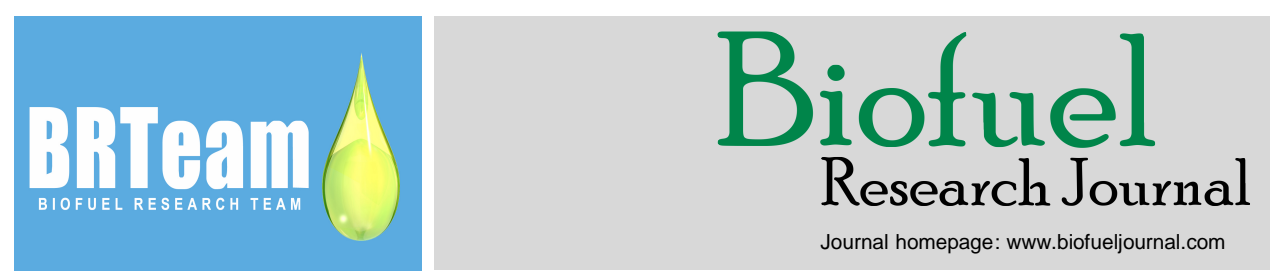

Original Research Paper

\title{
Alkaline modified A-site deficient perovskite catalyst surface with exsolved nanoparticles and functionality in biomass valorisation
}

\author{
Ahmed Umar ${ }^{1,2, *}$, Dragos Neagu ${ }^{1,3}$, John T.S. Irvine ${ }^{1, *}$ \\ ${ }^{1}$ School of Chemistry, University of St Andrews, North Haugh, St Andrews, Fife KY16 9ST, UK. \\ ${ }^{2}$ Department of Chemistry, University of Abuja, Gwagwalada, FCT, Abuja, Nigeria. \\ ${ }^{3}$ Department of Process and Chemical Engineering, University of Strathclyde, Glasgow, G1 1XL, UK.
}

\section{HIGHLIGHTS}

$>$ Catalyst design based on exsolved nanoparticles and basicity control is presented.

$>$ Incorporation and characterisation of alkaline metals in A-deficient perovskites.

$>$ Exsolved nanoparticles withstand coking in glycerol environment.

$>$ Relatively high selectivity and conversion of glycerol to hydrogen and syngas.

$>$ Structural and morphological design principles

achieved would be applicable in other fields

\section{GRAPHICAL ABSTRACT}

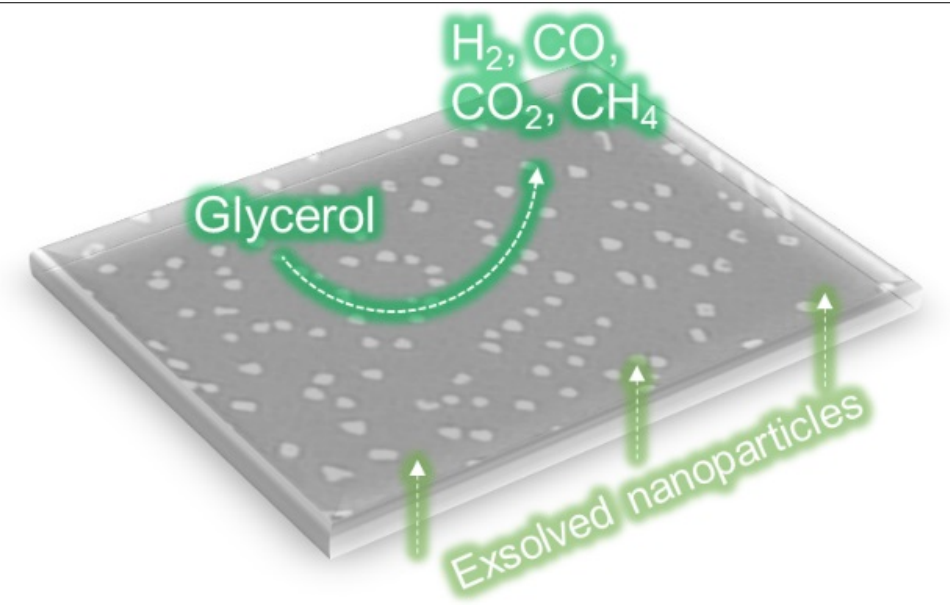

\section{ARTICLE INFO}

\section{Article history:}

Received 25 September 2020

Received in revised form 2 January 2021

Accepted 7 February 2021

Available online 1 March 2021

\section{Keywords:}

Surface chemistry

Steam reforming

Syngas

Biofuel

Fuel cell

\begin{abstract}
Environmental problems associated with the use of fossil fuels and increase in energy demands due to rise in population and rapid industrialisation, are the driving forces for energy. Catalytic conversion of biomass to renewable energies is among the promising approaches to materialize the above. This requires development of robust catalysts to suppress deactivation due to carbon deposition and agglomeration. In this work, surface properties and chemistry such as exsolution of B-site metal catalyst nanoparticles, particle size and distribution, as well as catalyst-support interactions were tailored through the use of alkaline dopants to enhance catalytic behaviour in valorisation of glycerol. The incorporation of alkaline metals into the lattice of an Asite deficient perovskite modified the surface basic properties and morphology with a consequent robust catalyst-support interaction. This resulted in promising catalytic behaviour of the materials where hydrogen selectivity of over $30 \%$ and $\mathrm{CO}$ selectivity of over $60 \%$ were observed. The catalyst ability to reduce fouling of the catalyst surface as a result of carbon deposition during operation was also profound due to the robust catalyst-support interaction occurring at the exsolved nanoparticles due to their socketing and the synergy between the dopant metals in the alloy in perovskite catalyst systems. In particular, one of the designed systems, $\mathrm{La}_{0.4} \mathrm{Sr}_{0.2} \mathrm{Ca}_{0.3} \mathrm{Ni}_{0.1} \mathrm{Ti}_{0.9} \mathrm{O}_{3 \pm \delta}$, displayed almost $100 \%$ resistance to carbon deposition. Therefore, lattice rearrangement using exsolution and choice of suitable dopant could be tailored to improve catalytic performance.
\end{abstract}

(C) 2021 BRTeam. All rights reserved.

Corresponding authors at:

E-mail address: u.ahmed2007@yahoo.com (Ahmed Umar) ; jtsi@ st-andrews.ac.uk (John T.S. Irvine)

Please cite this article as: Umar A., Neagu D., Irvine J.T.S. Alkaline modified A-site deficient perovskite catalyst surface with exsolved nanoparticles and functionality in biomass valorisation. Biofuel Research Journal 29 (2021) 1342-1350. DOI: 10.18331/BRJ2021.8.1.5 


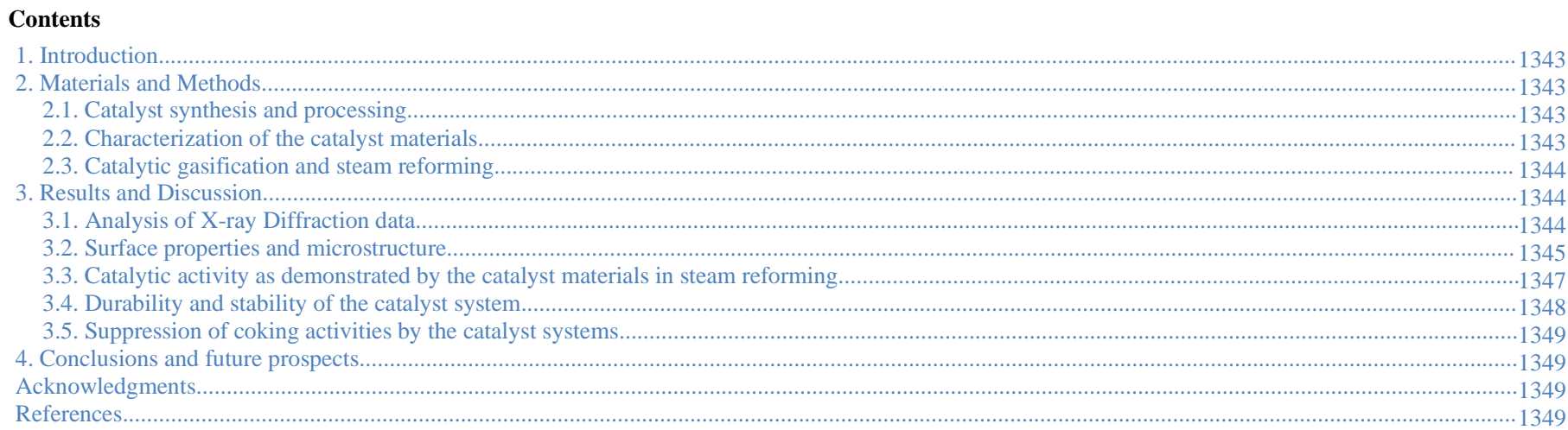

\section{Introduction}

Arguably, the quest for robust catalyst material systems with the suitable properties for industrial applications in the area of energy production such as fuel cell technology has yielded many interesting developments (Neagu and Irvine, 2011; Neagu et al., 2013). Remarkably, it has been recently shown that metal catalysts such as nickel nanoparticles could be produced at the surface oxide supports by means of thermal treatment in reducing atmosphere, in a socalled exsolution process (Neagu et al., 2015; Gao et al., 2017). This catalyst design offers some promising properties such as control over particle size, growth, distribution, and strong metal catalyst-support interaction for enhanced catalysis. This has multiple benefits over traditional supported metal catalysts using wet impregnation. The conventional wet impregnation/deposition or assembling technique may be time consuming and difficult to control particle size, growth, distribution and is known to lead to relatively week catalystsupport interaction (Perego and Villa, 1997; Lin, 2013). After the initial work by Nishihata et al. (2002) and Tanaka et al. (2006) on the intelligent, selfregenerating catalyst, the concept of exsolution has been brought forward by significant recent developments. For instance, Neagu et al. (2013) demonstrated that B-site exsolution could be achieved preferentially on the outer surface rather than in the bulk and even for less reducible cations, by tailoring and controlling the defect chemistry in A-site deficient, precious metal-free, titanate-based perovskite. Furthermore, this has enabled the design of much needed efficient and robust catalytic materials for fuels and energy conversion (Liu et al., 2016b; Myung et al., 2016). In exsolution, the metal nanoparticles are exsolved to the surface by ion migration from the bulk, occurring during reduction stage when oxygen is being removed and electrons doped into the perovskite. The exsolved nanoparticles confined and socketed in the perovskite surface, resulting in a robust catalyst-support interaction. This accounts for the enhanced catalytic behaviour and resistance to carbon deposition (Neagu et al., 2015; Du et al., 2016; Hui et al., 2018).

Catalysis and fuel cell technology are key in achieving a much desired clean and sustainable energy economy (Gao et al., 2016). In particular, the valorisation of glycerol from biodiesel synthesis (seen as a waste at the moment) for utilisation in fuel cell technology, is quite an innovative effort that is attracting much research interest and resources (Schwengber et al., 2016; Fasolini et al., 2019). Utilisation of glycerol by-product in fuel cell as renewable hydrogen resource, would add value to the transesterification 'waste product' and reduce cost of biodiesel production which is recently identified as one of the major problems hindering full commercialization of biodiesel production. Moreover, fouling of catalyst surface or cell degradation resulting in loss of performance, is also a challenge in the use of such renewable biomassbased fuels (McIntosh and Gorte, 2004; Neagu et al., 2015). Thus, there is need to develop robust catalysts that are not only resistant to carbon deposition but also highly active.

Perovskite materials such as the titanates can serve as supports for various catalytic and electro-catalytic processes due to multiple advantages including thermal and redox stability as well as doping flexibility (Neagu and Irvine, 2010; Wei et al., 2014). The latter allows for enhancing their properties and is accommodated by various lattice-level mechanism including octahedral tilting or stretching and existence of ion vacancies and defect chemistry (Neagu and Irvine, 2010; Neagu et al., 2013). Upon doping, titanates can exhibit reasonable catalytic properties, suitable morphology, microstructure, as well as ionic and electronic conductivity (Neagu et al., 2017; Zubenko et al., 2017). Surface activity can be further enhanced by exsolution, as explained above. Depending on the number of the exsolvable species, the exsolved metal catalysts may form as a single metal or as alloy of two or more metals. Generally, the synergy between the metals in the alloy in perovskite structures and between metal/metal oxide have yielded better results compared to single metal catalysts (Kitla et al., 2013; Zhongpeng et al. 2013; Papaioannou et al., 2019).

In this work, a series of new non-stoichiometric titanates systems with the general formula $(\mathrm{LaM})_{1-\alpha}(\mathrm{ZNi})_{\mathrm{x}} \mathrm{Ti}_{1-\mathrm{x}} \mathrm{O}_{3 \pm \delta}$ (where $\mathrm{M}=\mathrm{Ca}$ and $\mathrm{Sr}$, whils $\mathrm{Z}=\mathrm{Fe}$, and $\mathrm{Cr}$ while $\alpha=10 \%$ ) were designed and synthesized. The alkaline earth metals were doped into the A-site lattice to enhance surface basic properties and facilitate exsolution of B-site metal catalysts-Ni or Fe (firstrow transition metals). Additionally, the catalyst ability to resist fouling of catalyst surface due to carbon deposition is also demonstrated to further reveal their robust catalytic behaviour.

\section{Materials and Methods}

\subsection{Catalyst synthesis and processing}

The materials were prepared using the oxides, carbonate and nitrates of the corresponding metals by a modified solid-state synthesis reported previously (Neagu et al., 2013). All reagents used were of high purity and analytical grade. The oxides were pre-dried at $300-800{ }^{\circ} \mathrm{C}$ and weighed hot at $300{ }^{\circ} \mathrm{C}$ in a beaker. The nitrates were also weighed depending upon the formulation and added to the oxide in same container. To avoid agglomeration and to enhance dispersion, Hypermer KD-1 (polyester/polyamide copolymer) dispersant was added and the mixture was homogenised with the aid of ultrasonic probe in acetone and dried on hot plate followed by calcination at $1000{ }^{\circ} \mathrm{C}$. The samples were further sintered at $1400-1430{ }^{\circ} \mathrm{C}$ to obtain the phase, after they were milled to powder form in a planetary ball mill. Then reduction of the pre-reacted sample was carried out in a tubular furnace at $900{ }^{\circ} \mathrm{C}$ for $30 \mathrm{~h}$ under $5 \%$ $\mathrm{H}_{2} / \mathrm{Ar}$ mixture to exsolve the metal nanoparticles.

\subsection{Characterization of the catalyst materials}

Crystallographic data was collected on a Pan-Analytical Empyrean XRay Diffractometer (XRD) operating on reflection mode using $\mathrm{Cu}-\mathrm{K} \alpha_{1}$ radiation at $\lambda=1.5406 \AA$ and $2 \theta$ angle range of $10-90^{\circ}$ at room temperature for $1 \mathrm{~h}$.

Brunauer-Emmett-Teller (BET) surface area, Barrette-Joyner-Halenda (BJH) pore volume, and size were investigated on Micrometrics TriStar II 3020 model using nitrogen adsorption/desorption at $77.35 \mathrm{~K}$. Each sample was heated to $120^{\circ} \mathrm{C}$ for $3 \mathrm{~h}$ to remove adsorbed moisture and gases before the analysis.

Field Emission Scanning Electron Microscopy (FESEM) JEOL JSM6700F was used to investigate morphology and surface properties. 
Fouling of the used catalysts surface due to carbon deposition during catalysis was characterized using temperature programmed oxidation (TPO) on NETZSCH STA 449C thermogravimetric analyser equipped with Thermostar mass spectrometer. A known weight of the used catalyst was introduced into the thermogravimetric analyser. The system was then flushed with argon to dispose of any other gas in the system. Oxidation of the surface carbon to $\mathrm{CO}_{2}$ was achieved using $\mathrm{O}_{2}$ to $900{ }^{\circ} \mathrm{C}$. Gases generated were directed to the mass spectrometer for detection and analysis.

\subsection{Catalytic gasification and steam reforming}

Catalytic steam reforming of pure glycerol was performed in a fixed bed quartz tube reactor ( $8 \mathrm{~mm}$ internal diameter (ID), $10 \mathrm{~mm}$ outer diameter (OD) and $24 \mathrm{~cm}$ long) at $700{ }^{\circ} \mathrm{C}$ and atmospheric pressure. The schematic diagram of the reactor assembly is shown in Figure 1.

Temperature of the furnace and sample was monitored using thermocouple placed in proximity to the catalyst surface. Syringe Harvard apparatus 22 infusions pump supplied the glycerol-water mixture (steam/carbon ratio 3:1) at the flow rate of $0.019 \mathrm{~mL} / \mathrm{min}$ and weight hourly space velocity (WHSV) of 28 $\mathrm{h}^{-1}$ to a stainless-steel pipe wrapped with heating tape at $250{ }^{\circ} \mathrm{C}$ for vaporisation and mixing. The vaporised reactant mixture was introduced into the reactor by high purity carrier Helium gas at flow rate of $40 \mathrm{~mL} / \mathrm{min}$ and was controlled by mass flow controllers. All volumetric flows were taken at normal temperature and pressure (NTP). Reforming was observed for $2 \mathrm{~h}$ to screen the catalysts and
$10 \mathrm{~h}$ for time on stream (TOS)/stability test. Gaseous products were analysed using a gas chromatograph (GC) equipped with TCD (HP 6890 series) and mass spectrometer residual gas analyser. The stability test was carried out at constant temperature of $700{ }^{\circ} \mathrm{C}$ at a heating of $5{ }^{\circ} \mathrm{C}$ under the helium gas carrier. The system was allowed to attain the required temperature and stabilised before the glycerol feedstock began to flow continuously for $10 \mathrm{~h}$.

\section{Results and Discussion}

\subsection{Analysis of X-ray Diffraction data}

The crystallographic data obtained at room temperature was used to ascertain the phase purity of the synthesised catalyst systems. The catalyst materials $\mathrm{La}_{0.4} \mathrm{Sr}_{0.2} \mathrm{Ca}_{0.3} \mathrm{Ni}_{0.1} \mathrm{Ti}_{0.9} \mathrm{O}_{3-\delta}(\mathrm{LSrCaNT}), \mathrm{La}_{0.8} \mathrm{Ca}_{0.1} \mathrm{Cr}_{0.2} \mathrm{Ni}_{0.2} \mathrm{Ti}_{0.6} \mathrm{O}_{3}$ ${ }_{\delta}(\mathrm{LCaCrNT})$, and $\mathrm{La}_{0.5} \mathrm{Sr}_{0.4} \mathrm{Fe}_{0.1} \mathrm{Ni}_{0.1} \mathrm{Ti}_{0.8} \mathrm{O}_{3-\delta}$ (LSrFNT) were designed and used in this work. All materials were designed and synthesized with A-site deficiency of $10 \%$. The XRD patterns shown in Figure 2 suggest that all materials were successfully synthesised and are in pure phase. Indexing of the pattern as shown in Figure 2a and b indicates that all the peaks or reflections are due to perovskites (Tsekouras et al., 2013). There is a shift in the position of the $2 \theta$ angle among the overlaid peaks as results of the different sizes and symmetry of the dopant and perhaps doping ratio used as corroborated by the refinement data provided in Table 1 . The stability

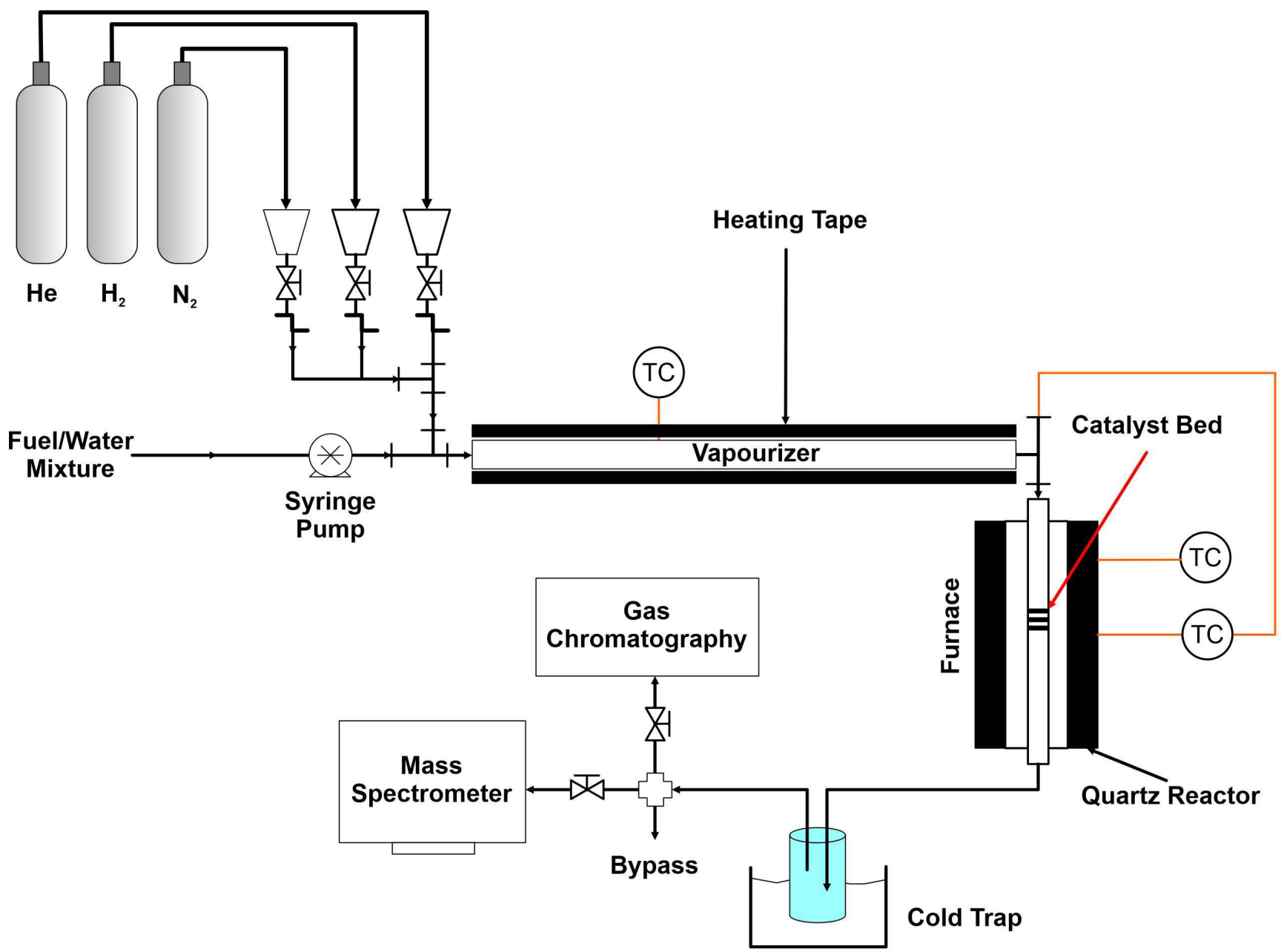

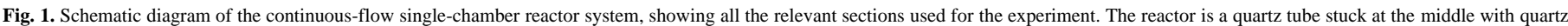
wool as catalyst bed and catalyst placed on the surface for contact with the incoming vaporized glycerol. 
$\mathbf{a}$

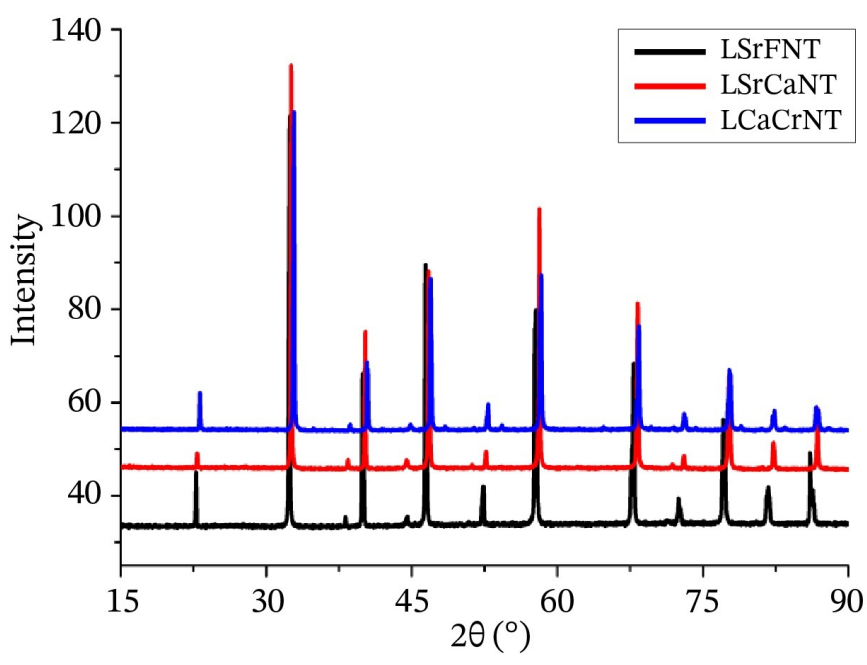

b

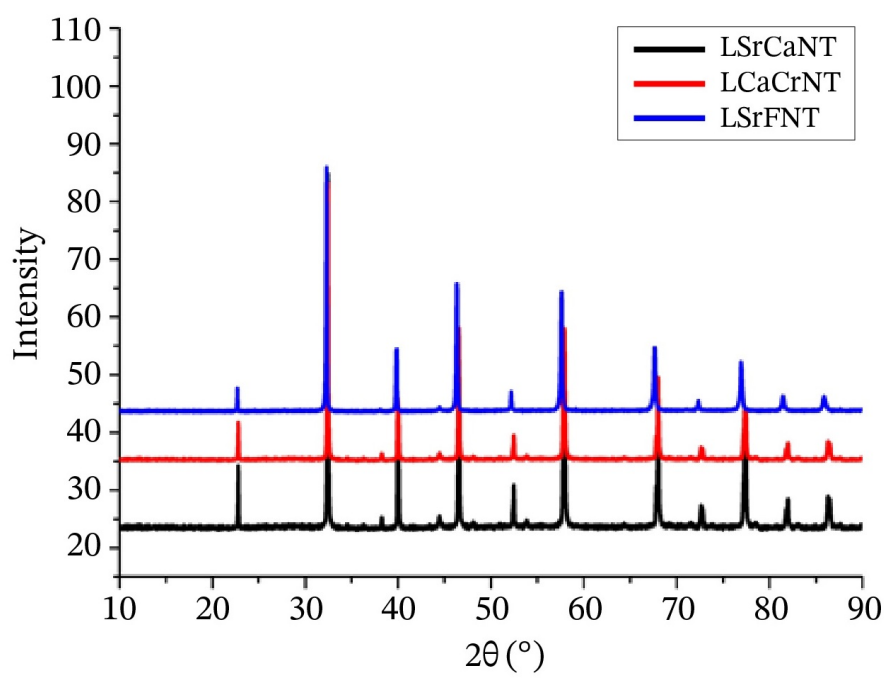

Fig. 2. The XRD patterns of the synthesized A-site deficient nickel-doped titanate perovskites for the samples showing their phase purity. (a) the as prepared samples prior to reduction and (b) the reduced samples. The figures and indexing confirmed their purity. It is also clear from the figure that the perovskite materials maintained their structure with no evidence of decomposition or disintegration after intense reduction for $30 \mathrm{~h}$ at $900^{\circ} \mathrm{C}$.

of the materials in hydrogen environment is robust as demonstrated by the XRD pattern of the reduced materials in Figure $2 \mathrm{~b}$. There is no evidence of decomposition of the perovskite structure after intense reduction for $30 \mathrm{~h}$ at 900 ${ }^{\circ} \mathrm{C}$. Though it is observable that the splitting pattern and intensity of peaks in the reduced pattern (Fig. $2 \mathrm{~b}$ ) are less when compared to the pattern of the asprepared materials (before reduction). This suggests the evolution of the reduced materials to lower symmetry. The shift to smaller $2 \theta$ by the reduced samples implies an increase in d-spacing. This is attributable to increase in the cell volume due to redox properties of the titania where electron during reduction changed the smaller $\mathrm{Ti}^{+4}$ ions to bigger $\mathrm{Ti}^{3+}$.

Rietveld refinement of the data collected for the samples as shown in Table 1 allowed the determination of space group, lattice parameter ' $a$ ', and cell volume. These parameters vary amongst the catalyst systems reflecting different ionic sizes of dopant used in the design. Though ionic size changes down the group and across the period on the periodic table, it is really difficult
Table 1.

Refinement data collected for the nickel-doped catalysts.

\begin{tabular}{lcccc}
\hline Catalyst & $\begin{array}{c}\text { Space } \\
\text { group }\end{array}$ & $\begin{array}{c}\text { Cell } \\
\text { parameter }\end{array}$ & $\begin{array}{c}\text { Cell } \\
\text { volume }\end{array}$ & $\begin{array}{c}\text { Refinement fit } \\
\text { parameter }\end{array}$ \\
\hline & & $\mathrm{a}=5.4894$ & & $\mathrm{R}_{\mathrm{p}}=8.53$, \\
$\mathrm{La}_{0.4} \mathrm{Sr}_{0.2} \mathrm{Ca}_{0.3} \mathrm{Ni}_{0.1} \mathrm{Ti}_{0.9} \mathrm{O}_{3-\delta}$ & $I 4 / m c m$ & $\mathrm{~b}=5.4894$ & 234.22 & $\begin{array}{c}\mathrm{R}_{\mathrm{wp}}=10.6, \\
\mathrm{c}=7.7729\end{array}$ \\
& & & $\begin{array}{c}\mathrm{R}_{\mathrm{Exp}}=11.43, \\
\mathrm{X}^{2}=0.661\end{array}$ \\
& & $\mathrm{a}=7.8009$ & & $\mathrm{R}_{\mathrm{p}}=11.1$, \\
$\mathrm{La}_{0.5} \mathrm{Sr}_{0.4} \mathrm{Fe}_{0.1} \mathrm{Ni}_{0.1} \mathrm{Ti}_{0.8} \mathrm{O}_{3-\delta}$ & $I 2 / a$ & $\mathrm{~b}=5.5387$ & 238.454 & $\mathrm{R}_{\mathrm{wp}}=15.3$, \\
& & $\mathrm{c}=5.5188$ & & $\mathrm{R}_{\mathrm{Exp}}=10.45$, \\
& & & & $\mathrm{X}^{2}=2.13$ \\
& & $\mathrm{a}=5.5246$ & & $\mathrm{R}_{\mathrm{p}}=7.24$, \\
$\mathrm{La}_{0.8} \mathrm{Ca}_{0.1} \mathrm{Cr}_{0.2} \mathrm{Ni}_{0.2} \mathrm{Ti}_{0.6} \mathrm{O}_{3-\delta}$ & $P b n m$ & $\mathrm{~b}=5.0547$ & 236.746 & $\mathrm{R}_{\mathrm{wp}}=9.69$, \\
& & $\mathrm{c}=7.7836$ & & $\mathrm{R}_{\mathrm{Exp}}=10.93$, \\
& & & & $\mathrm{X}^{2}=0.787$ \\
\hline
\end{tabular}

to make a good correlation which reflects what is observable on the periodic table because of the complexity of the design. This is because other ions in the design aside alkaline metals also contribute to the observed variation of the parameters.

The original XRD pattern of the synthesised materials showed a good matching and correlation with the refinement model and the proposed space groups as seen in Figure 3a-c. This further strengthened the phase purity of the synthesised catalyst systems. Crystal model is also provided to show the orientation of the atoms in space and octahedral distortions, i.e., in-outof-phase tilting further reflecting and corroborating the influence and role of the dopant ions.

Although the level of A-site deficiency is the same in all the samples, the different space groups, cell volumes, and lattice parameter obtained are a clear manifestation of the influence of varying dopants used. These catalytic properties are also expected to reflect in the catalytic behaviour of the systems.

\subsection{Surface properties and microstructure}

Surface properties such as surface area, pore size and volume were investigated and the result obtained from the analysis is shown in Table 2. The results show that the surface area of the as prepared materials was enhanced after the reduction. This is attributable to the fact that the exsolved catalyst nanoparticles are dispersed and decorated on the titanium oxide surface as shown by the SEM micrograph in Figure 4, which has modified the surface morphology resulting to the larger surface area. $\mathrm{La}_{0.4} \mathrm{Sr}_{0.2} \mathrm{Ca}_{0.3} \mathrm{Ni}_{0.1} \mathrm{Ti}_{0.9} \mathrm{O}_{3-\delta}$ and $\mathrm{La}_{0.8} \mathrm{Ca}_{0.1} \mathrm{Cr}_{0.2} \mathrm{Ni}_{0.2} \mathrm{Ti}_{0.6} \mathrm{O}_{3-\delta}$ surface area were better enhanced relatively compared to the $\mathrm{La}_{0.5} \mathrm{Sr}_{0.4} \mathrm{Fe}_{0.1} \mathrm{Ni}_{0.1} \mathrm{Ti}_{0.8} \mathrm{O}_{3-\delta}$ catalyst. Generally, perovskite materials synthesised by the conventional methods have yielded small surface area in the range of $1-15 \mathrm{~m}^{2} / \mathrm{g}$ which is not much suitable for a supported metal catalyst (Yasutake et al., 2000; Evans et al., 2016). Efforts being made to enhance surface area and morphology of perovskite materials to improve catalytic activity such as the use of template (Afzal et al., 2017; Chen et al., 2019) and exsolution (Lindenthal et al., 2020; Kwon et al., 2020). Such efforts have proved useful and compares favourably with the results obtained in this work. Considering the method of preparation (solid state synthesis) used herein which does not much enhance surface area and the high sintering temperature used in calcination, the materials showed reasonable surface area nonetheless after exsolution when compared to other methods used in related work (Chen et al., 2019). Results of the catalysis of the reformates from glycerol decomposition and gasification in this work illustrated in Figure 5a and b go to further support this observation.

Microstructure and morphology of the catalyst systems was also investigated to assess the extent of exsolution of the catalyst nanoparticle, their dispersion or distribution as well as suitability or otherwise of the surface for catalysis. The materials showed some level of exsolution of the catalyst particles as shown in Figure 4a, b, and c.

The exsolved nanoparticle metal catalysts are uniformly distributed on the surface and are largely $\mathrm{Ni}$ as well as $\mathrm{Ni}-\mathrm{Fe}$ alloy grown from the parent perovskite lattice structure. The alloys are likely to demonstrate enhanced catalytic activity, suppression of carbon deposition as well as reducibility 


\section{$\mathbf{a}$}
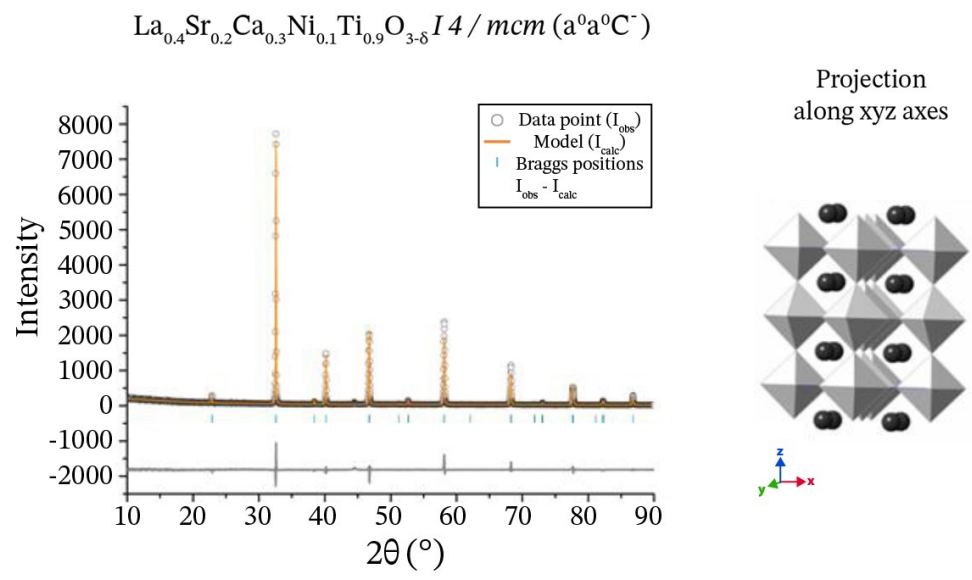

$$
\begin{aligned}
& \text { Projection } \\
& \text { along y axis }
\end{aligned}
$$

Projection

along $\mathrm{z}$ axis

\section{b}

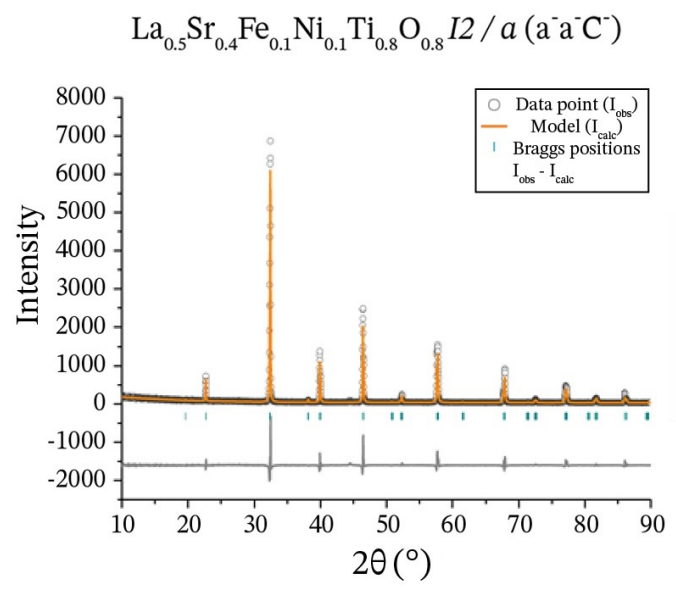

$$
\begin{gathered}
\text { Projection } \\
\text { along xyz axes }
\end{gathered}
$$
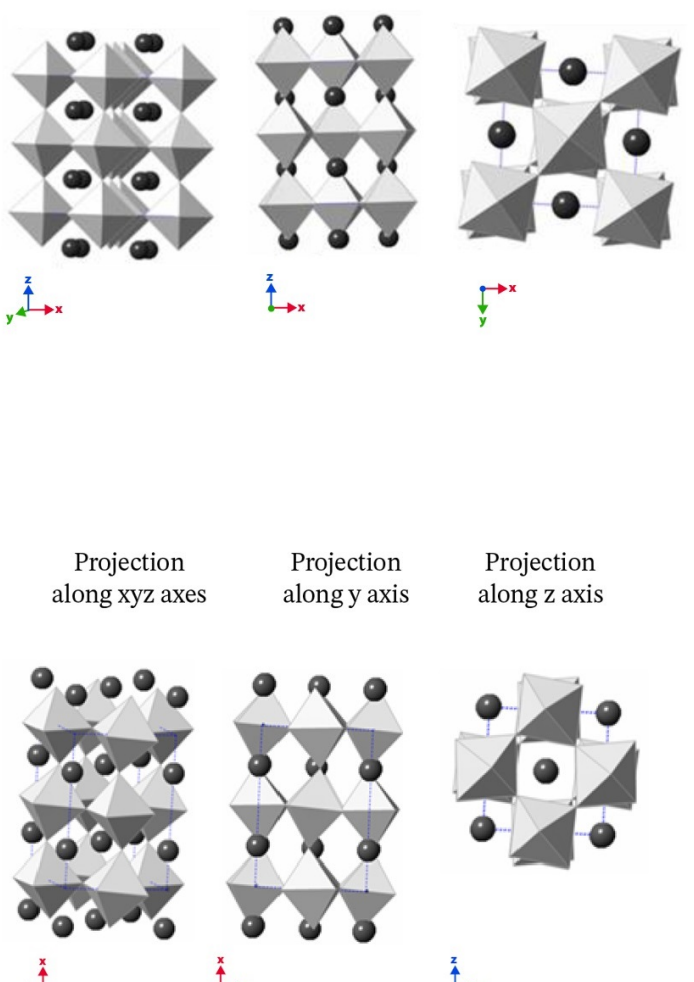<smiles>C1[C]2CC1C2</smiles>

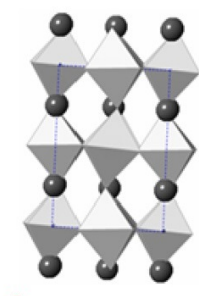

C

$\mathrm{La}_{0.8} \mathrm{Sr}_{0.1} \mathrm{Cr}_{0.2} \mathrm{Ni}_{0.2} \mathrm{Ti}_{0.6} \mathrm{O}_{3-\delta} \mathrm{Pbnm}\left(\mathrm{a}^{-} \mathrm{a}^{-} \mathrm{C}^{+}\right)$

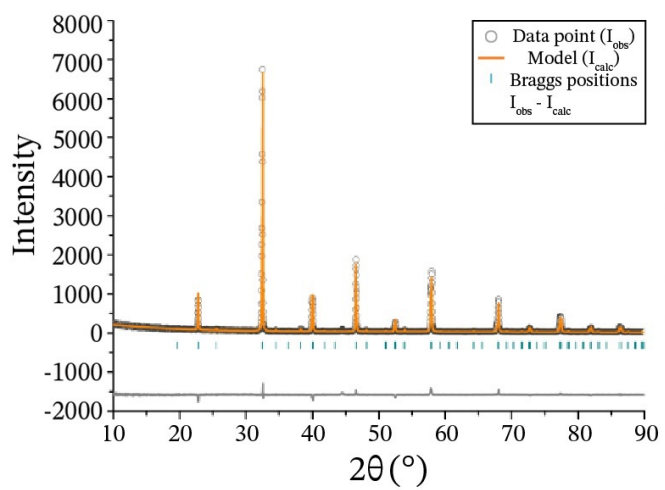

Projection along xyz axes

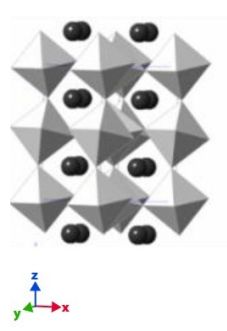

Projection along y axis

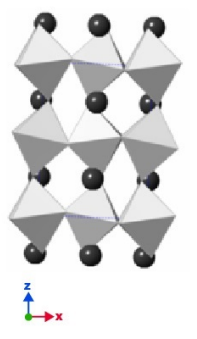

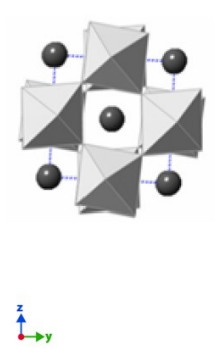

$\begin{array}{cc}\begin{array}{c}\text { Projection } \\ \text { along y axis }\end{array} & \begin{array}{c}\text { Projection } \\ \text { along } \mathrm{z} \text { axis }\end{array}\end{array}$

$\begin{array}{cc}\begin{array}{c}\text { Projection } \\ \text { along y axis }\end{array} & \begin{array}{c}\text { Projection } \\ \text { along } \mathrm{z} \text { axis }\end{array}\end{array}$

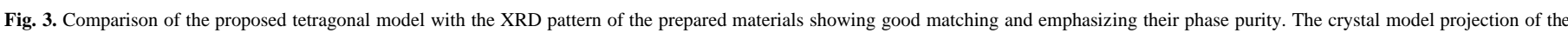

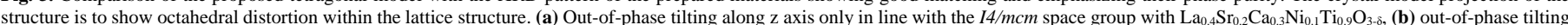

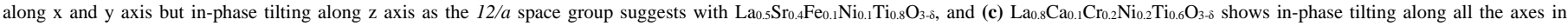
agreement with $\mathrm{p} \mathrm{b} \mathrm{n} \mathrm{m} \mathrm{space} \mathrm{group.}$ 
Table 2.

Surface properties of the materials before and after reduction.

\begin{tabular}{lcc}
\hline Catalyst Systems & $\begin{array}{c}\text { Surface Area before } \\
\text { Reduction }\left(\mathbf{m}^{2} / \mathbf{g}\right)\end{array}$ & $\begin{array}{c}\text { Surface Area After } \\
\text { Reduction }\left(\mathbf{m}^{2} / \mathbf{g}\right)\end{array}$ \\
\hline $\mathrm{La}_{0.4} \mathrm{Sr}_{0.2} \mathrm{Ca}_{0.3} \mathrm{Ni}_{0.1} \mathrm{Ti}_{0.9} \mathrm{O}_{3-\delta}$ & 2.9 & 8.8 \\
$\mathrm{La}_{0.8} \mathrm{Ca}_{0.1} \mathrm{Cr}_{0.2} \mathrm{Ni}_{0.2} \mathrm{Ti}_{0.6} \mathrm{O}_{3-\delta}$ & 2.0 & 4.2 \\
$\mathrm{La}_{0.5} \mathrm{Sr}_{0.4} \mathrm{Fe}_{0.1} \mathrm{Ni}_{0.1} \mathrm{Ti}_{0.8} \mathrm{O}_{3-\delta}$ & 1.6 & 2.5 \\
\hline
\end{tabular}

3.3. Catalytic activity as demonstrated by the catalyst materials in steam reforming

The catalytic activity of the prepared catalyst materials was investigated at $700{ }^{\circ} \mathrm{C}$ using pure glycerol at $2.60 \times 10^{-4} \mathrm{~mol} / \mathrm{min}$ molar flow rate of glycerol-water solution and WHSV of $28 \mathrm{~h}^{-1}$. Steam-carbon ratio of $1: 3$ was maintained throughout the duration of the test. The efficacy of the catalyst systems in the production of some useful gases was used to evaluate catalytic activity. The result obtained as shown in Figure 5a and b gives
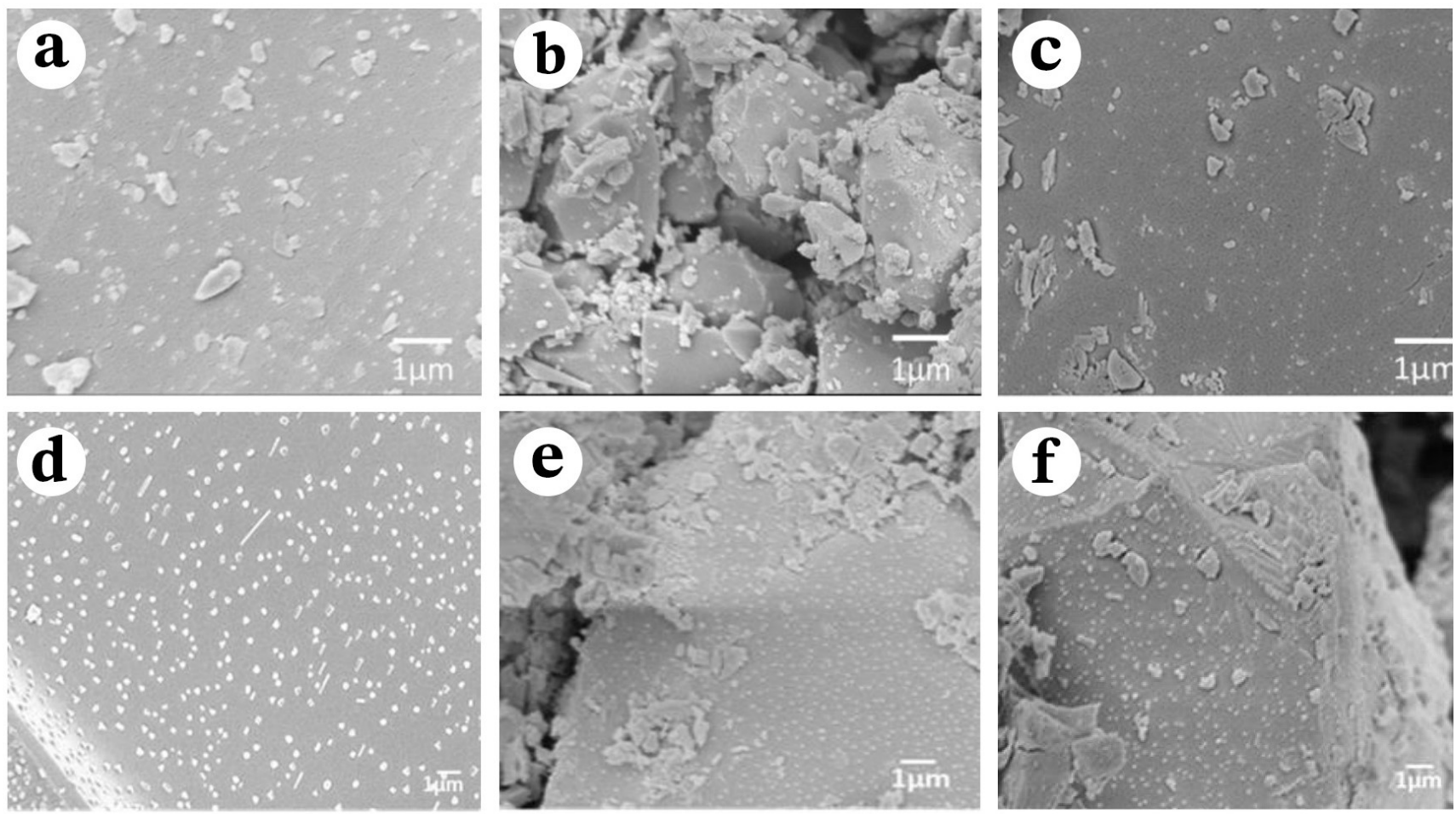

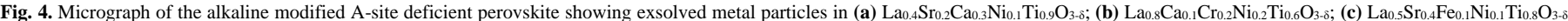
(d) $\mathrm{La}_{0.6} \mathrm{Ce}_{0.05} \mathrm{Sr}_{0.1} \mathrm{Ni}_{0.1} \mathrm{Ti}_{0.9} \mathrm{O}_{3-\delta} ;$ (e) $\mathrm{La}_{0.8} \mathrm{Ce}_{0.1} \mathrm{Ni}_{0.4} \mathrm{Ti}_{0.6} \mathrm{O}_{3-\delta} ;$ and (f) $\mathrm{La}_{0.7} \mathrm{Ce}_{0.1} \mathrm{Fe}_{0.3} \mathrm{Ni}_{0.1} \mathrm{Ti}_{0.6} \mathrm{O}_{3-\delta}$.

of the nickel particles for effective catalytic behaviour relatively when compared to other materials prepared by impregnation (Wu et al., 2014; Liu et al., 2016a; Papaioannou et al., 2019). This is attributable to their redox stability particularly the chromia-doped titania, enhanced catalyst-support interaction due to exsolution, and synergy between the combined catalyst particles in the alloy as reported in related studies (Tao and Irvine, 2004a; Papaoannou et al., 2019). Moreover, the constituent alkaline dopant metals; calcium and strontium enhanced acidic-basic sites and strengthened the nickel behaviour in C-C bond cracking and gasification of glycerol. Interestingly, all materials were designed with A-site deficiency of $10 \%$ for easy correlation, they only vary in terms of the dopant cations and doping ratios used. Therefore, the disparity in the degree of exsolution of B-site nanocatalyst shown by the materials in Figure 4 can be attributed to influence of dopants. However, it is observed that the level of exsolution with the alkaline modified materials is not as good when compared to similar materials doped with ceria (Figure $4 \mathrm{c}$, d, and e) that are not part of this work. This is attributable to strontium that is known to 'hinder' exsolution of B-site cations (Neagu et al., 2015; Papaloannou et al., 2019). It is interesting to note that the contribution of dopant metal on the exsolution of catalyst particle is clearly manifested in Figure 4 between the non-ceria and ceriadoped materials. The ceria-doped better demonstrated exsolution phenomenon than what is seen with the non-ceria materials. the ratio of the predominant gas composition been $\mathrm{H}_{2}$ and $\mathrm{CO}$ as well as $\mathrm{CO}_{2}$ from the catalytic test plotted against the respective catalyst systems in comparison with equilibrium composition. Other gaseous products detected along with the predominant $\mathrm{H}_{2}$ and $\mathrm{CO}$ are $\mathrm{CO}_{2}$ and $\mathrm{CH}_{4}$, respectively, as shown in Figure 5b.

This suggests that the exsolved catalysts are active as the non-exsolved catalyst yielded no activity. The $\mathrm{La}_{0.4} \mathrm{Sr}_{0.2} \mathrm{Ca}_{0.3} \mathrm{Ni}_{0.1} \mathrm{Ti}_{0.9} \mathrm{O}_{3-\delta}$ was found to be more active whilst $\mathrm{La}_{0.8} \mathrm{Ca}_{0.1} \mathrm{Cr}_{0.2} \mathrm{Ni}_{0.2} \mathrm{Ti}_{0.6} \mathrm{O}_{3-\delta}$ was the least active. The performance of the two best is attributed to the highly basic sites due to $\mathrm{Ca}$ and $\mathrm{Sr}$ dopants in $\mathrm{La}_{0.4} \mathrm{Sr}_{0.2} \mathrm{Ca}_{0.3} \mathrm{Ni}_{0.1} \mathrm{Ti}_{0.9} \mathrm{O}_{3-\delta}$ and the influence of the synergy due to $\mathrm{Ni}-\mathrm{Fe}$ alloy in $\mathrm{La}_{0.5} \mathrm{Sr}_{0.4} \mathrm{Fe}_{0.1} \mathrm{Ni}_{0.1} \mathrm{Ti}_{0.8} \mathrm{O}_{3-\delta}$ in addition to the basic sites. The catalytic activity is comparable to what was reported by Ramesh and Venkatesha (2017) and Papaioannou et al. (2019). The prevalence of the predominant gases is attributable to the exsolved nickel particles and rapid pyrolysis due to kinetic which has facilitated the gasification and oxidation of the glycerol carbonaceous decomposition products leading to the formation of $\mathrm{CO}$ as supported in related works ( $\mathrm{Wu}$ et al., 2014; Ramesh and Venkatesha, 2017). Other contributing factor that might have influenced the observed catalytic behaviour is the reverse water gas shift reaction (RWGSR). These observations are well manifested and corroborated by the robust suppression of carbon deposition demonstrated 
$\mathbf{a}$

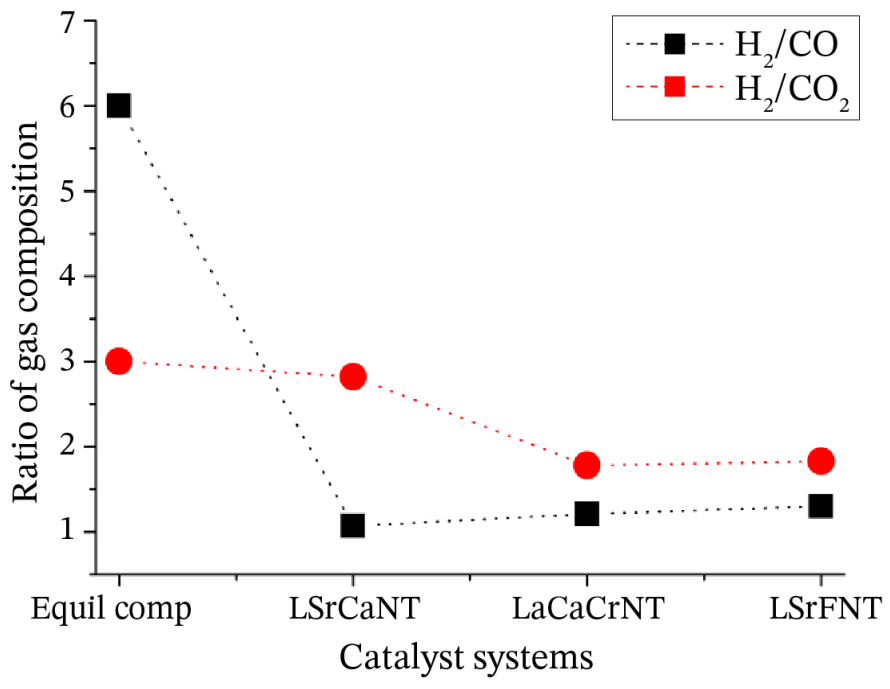

b

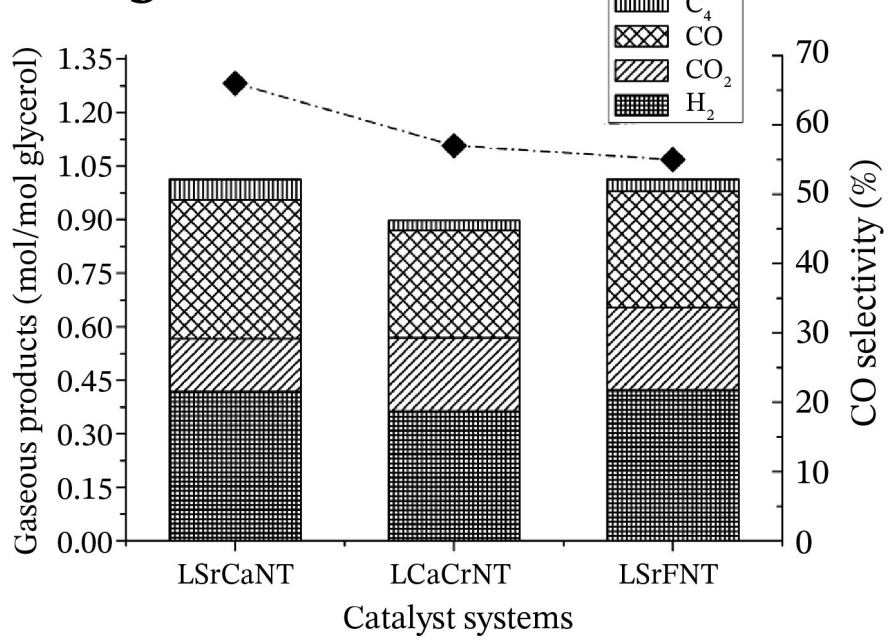

Fig. 5. Catalytic activity expressed as (a) ratio of predominant gases against respective catalyst systems and (b) comparison of the hydrogen produced and other gaseous products in $\mathrm{mol} / \mathrm{mol}$ glycerol with $\mathrm{CO}$ selectivity. Both figures reflect the extent of the catalytic activity and selectivity of the catalyst systems for the desired products.

by the materials as a result of rapid oxidation of carbonaceous products from the decomposed glycerol feedstock (See Section 3.5).

Although $\mathrm{CO}_{2}$ and $\mathrm{H}_{2}$ were generated as well as a result of $\mathrm{Ni}$ and $\mathrm{Ni}-\mathrm{Fe}$ alloy propensity for water-gas-shift reaction (WGSR) (Popovic, et al., 2020), the hydrogen production could be influenced by the reaction and material processing conditions. This includes the high temperature employed during sintering and reduction process on the samples in this work which would have reduced the surface area of the materials. RWGSR favoured by the catalyst system and other reactions leading to the formation of acrolein and carbonyl compounds also contributed. Throughput due to low catalyst bed thickness as a result of small amount of catalyst used from the test $(50 \mathrm{mg})$ is also likely to reduce the contact time and the product dissemination from the reactions. Nonetheless, the results show that the catalyst materials are quite suitable for hydrogen and syngas production. Figure $5 \mathrm{~b}$ depicts a correlation between the gaseous products in $\mathrm{mol} / \mathrm{mol}$ glycerol and selectivity for $\mathrm{CO}$ been one of the predominant gaseous products. It is evident that the catalysts are good for syngas production, especially $\mathrm{La}_{0.4} \mathrm{Sr}_{0.2} \mathrm{Ca}_{0.3} \mathrm{Ni}_{0.1} \mathrm{Ti}_{0.9} \mathrm{O}_{3-\delta}$ due to its high basic surface from $\mathrm{Ca}$ and $\mathrm{Sr}$ dopant. The catalytic activity has manifested not only in the oxidation of the carbonaceous glycerol decomposition products leading to the generation of hydrogen rich gas or syngas, but also in the suppression of carbon deposition as corroborated by the result of the catalyst test and coke suppression, presented in Section 3.5. The syngas produced could be used as alternative renewable hydrogen fuel for utilisation in a variety of processes in the area of energy production such as in solid oxide fuel cell.

\subsection{Durability and stability of the catalyst system}

The catalysts systems were tested for several hours to further analyse their activity as well as stability to deactivation as a result of carbon deposition, catalyst sintering, or poisoning due to prolonged usage in gaseous stream. The test was carried out by monitoring hydrogen production per mole of glycerol over time for $10 \mathrm{~h}$. The test was performed at $700{ }^{\circ} \mathrm{C}$ using a continuous flow of pure glycerol-water mixture at the rate of $2.60 \times 10^{-4} \mathrm{~mol} / \mathrm{min}$ and steam-to-carbon ratio of 3:1 at atmospheric pressure and WHSV of $28 \mathrm{~h}^{-1}$. The result obtained is as shown in Figure 6 . Considering the trend of activity in Figure 6, all the catalyst systems showed good activity and stability with only a slight drop within the first three hours with catalyst systems $\mathrm{La}_{0.4} \mathrm{Sr}_{0.2} \mathrm{Ca}_{0.3} \mathrm{Ni}_{0.1} \mathrm{Ti}_{0.9} \mathrm{O}_{3-\delta}$ and $\mathrm{La}_{0.5} \mathrm{Sr}_{0.4} \mathrm{Fe}_{0.1} \mathrm{Ni}_{0.1} \mathrm{Ti}_{0.8} \mathrm{O}_{3-\delta}$, then, stabilization of stability was resumed thereafter. The catalytic behaviour of the perovskite observed in this case, can be compared to what was reported in related works by Chen et al. (2019) and Ramesh and Venkatesha (2017). The chromium-doped system has shown better stability which is typical of chromium-based systems (Tao and Irvine, 2004a and b). These attest to the fact that the catalyst systems are quite active and stable and could be used as a guide in tailoring and design of robust catalyst systems.

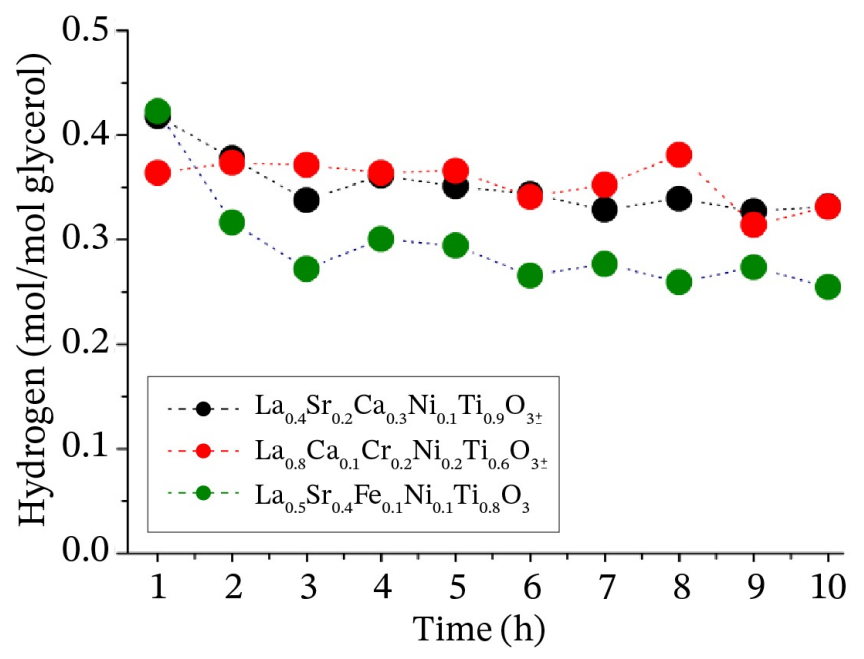

Fig. 6. The catalytic activity and stability of the materials showing how the hydrogen produced in $\mathrm{mol} / \mathrm{mol}$ of glycerol changes over time.

Moreover, the basic property and suitability of the dopant metal used enhanced rapid oxidation of carbonaceous decomposition products from the glycerol feedstock which helped to suppress the carbon deposition and improve stability of the catalysts. Consequently, the catalyst systems demonstrated high products selectivity and stability in gasification and steam reforming of glycerol for hydrogen production as well as resistance against fouling of catalyst surface by coke (Fig. 7). Hence, the synergy between alkaline surface due to the dopant metal used and defect chemistry could be explored in catalyst design for effective gasification of feedstock such as glycerol to produce hydrogen and syngas. 


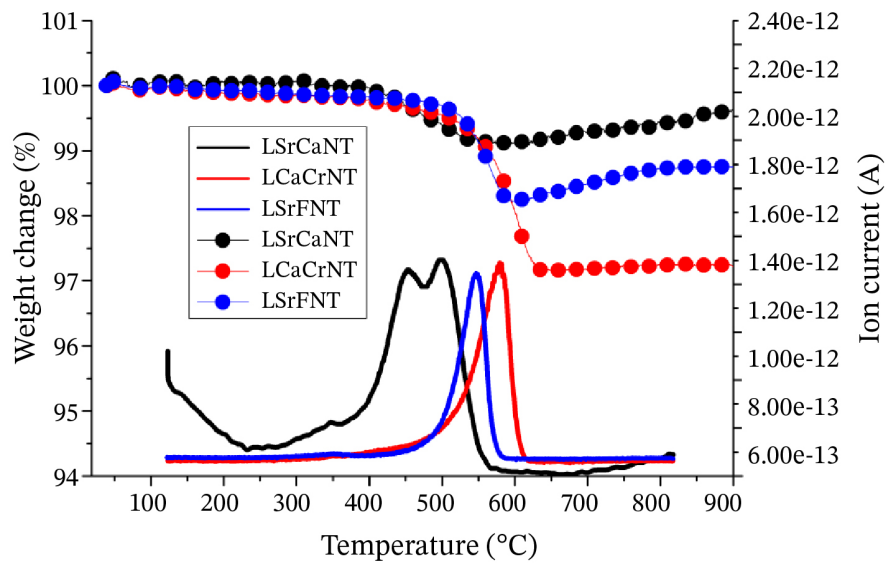

Fig. 7. Change in weight from oxidation of carbon from surface of the used catalyst in an oxidising atmosphere, monitored in parallel with $\mathrm{CO}_{2}$ as a function of temperature. The $\mathrm{CO}_{2}$ peak indicates the temperature at which carbon oxidised which depends on the nature and location of the carbon whilst the TGA profile shows the extent of coking.

\subsection{Suppression of coking activities by the catalyst systems}

To investigate the level of carbon deposition with the view of understating how the materials were able to suppress coking activities, the used catalyst after $10 \mathrm{~h}$ of continuous test was subjected to temperature programmed oxidation and the result is shown in Figure 7. The temperature at which bulk of the carbon was oxidised and weight lost on the thermogravimetric analysis (TGA) was used to assess the nature of the coke and extent of the coking activities, respectively.

Generally, the TGA profile showed a gentle weight loss among all the used catalysts which suggests a mild coking was recorded for all. This also suggests a robust suppression of coking by these catalyst materials as is known with perovskite catalyst of this design (Neagu et al., 2015; Sun et al., 2016). This is attributable to the basic surface properties due to the alkaline dopant as well as lattice A-site deficiency that are known to enhance rapid oxidation of carbonaceous gases from glycerol decomposition. The $\mathrm{La}_{0.4} \mathrm{Sr}_{0.2} \mathrm{Ca}_{0.3} \mathrm{Ni}_{0.1} \mathrm{Ti}_{0.9} \mathrm{O}_{3-\delta}$ titinate stood out among the other catalysts almost completely hindering carbon deposition. This is attributed to the good catalystsupport interaction from the exsolved particles as well as basic character of the strongly basic alkaline earth metal-Ca and $\mathrm{Sr}$ dopants added to it. The nature and location of its carbon was also different relatively. Its carbon was oxidised at lower temperature $\left(400-500^{\circ} \mathrm{C}\right)$ which depicts an easy-to-oxidise amorphous carbon deposited on the catalyst metal surface. Whilst both $\mathrm{La}_{0.8} \mathrm{Ca}_{0.1} \mathrm{Cr}_{0.2} \mathrm{Ni}_{0.2} \mathrm{Ti}_{0.6} \mathrm{O}_{3-\delta}$ and $\mathrm{La}_{0.5} \mathrm{Sr}_{0.4} \mathrm{Fe}_{0.1} \mathrm{Ni}_{0.1} \mathrm{Ti}_{0.8} \mathrm{O}_{3-\delta}$ have their corresponding $\mathrm{CO}_{2}$ peaks at intermediate temperatures $\left(500-600{ }^{\circ} \mathrm{C}\right)$ which depict polymeric or graphitic carbon deposited at metal-support interphase.

\section{Conclusions and future prospects}

The present work revealed that catalytic properties could be tailored using suitable dopants to modify surface chemistry for enhanced structural properties such as robust catalyst-support interaction and suitable surface morphology to achieve promising catalytic behaviours. The alkaline earth-lattice defect mediated exsolved B-site metal alloy particles were anchored and socketed on the thermally-stable titanate oxide support. These showed some interesting surface properties, chemistry and design such as improved catalyst-support properties, particle size and distribution as well as thermal stability against agglomeration and catalyst deactivation. The perovskite structured materials demonstrated some catalytic activity in gasification and steam reforming of renewable feedstock such as glycerol to generate hydrogen and syngas. The robust active nature of the catalyst systems was more importantly manifested in prolonging the catalyst durability and ability to suppress carbon and catalyst deactivation. The catalysts have much prospect in production of hydrogen and syngas that could be used in a variety of ways in the area of energy production.
Therefore, other alkaline earth metals should be investigated in future and dopant ratio should be optimised to get the best catalyst formulation. Influence of other parameters such as temperature, catalyst amount, reaction time, etc. should also be taken into account to come up with best reaction condition that would ensure maximum yield. First raw transition metals such as $\mathrm{Co}, \mathrm{Cu}$, and $\mathrm{Mn}$ could be substituted on the B-site to enhance catalytic behaviour. Reforming other liquid feedstocks for hydrogen production should also be investigated.

\section{Acknowledgements}

The authors would like to thank the Petroleum Technology Development Fund (Nigeria) for funding this research and University of St Andrews (Scotland, UK) for the opportunity to carry out the research.

\section{References}

[1] Afzal, S., Quan, X., Zhang, J., 2017. High surface area mesoporous nanocast $\mathrm{LaMO}_{3}(\mathrm{M}=\mathrm{Mn}, \mathrm{Fe})$ perovskite for efficient catalytic ozonation and an insight into probable catalytic mechanism. Appl. Catal., B. 206, 692-703.

[2] Chen, C., Meng, Z. Wang, Z., 2019. Large specific surface area macroporous nanocast $\mathrm{LaFe}_{1-\mathrm{x}} \mathrm{Ni}_{\mathrm{x}} \mathrm{O}_{3}$ : a stable catalyst for catalytic methane dry reforming. Hindawi J. Chem. 1-9.

[3] Du, Z., Zhao, H., Yi, S., Xia, Q., Gong, Y., Zhang, Y., Cheng, X., Li, Y., Lin, Gu, L., Swierczek, Z., 2016. High-performance anode material $\mathrm{Sr}_{2} \mathrm{FeMo}_{0.65} \mathrm{Ni}_{0.35} \mathrm{O}_{6-\delta}$ with in situ exsolved nanoparticle catalyst. ACS Nano. 10(9), 8660-8669.

[4] Evans, C.D., Kondrat, S.A., Smith, P.J., Manning, T.D., Miedziak, P.J., Brett, G.L., Armstrong, R.D., Bartley, J.K., Taylor, S.H., Rosseinsky, M.J., Hutchings, G.J., 2016. The preparation of large surface area lanthanum based perovskite supports for AuPt nanoparticles: tuning the glycerol oxidation reaction pathway by switching the perovskite B site. Faraday Discuss. 188, 427-450.

[5] Fasolini, A., Cespi, D., Tabanelli, T., Cucciniello, R., Cavani, F., 2019. Hydrogen from renewables: a case study of glycerol reforming. Catalyst. 9(9), 722

[6] Gao, Y., Chen, D., Saccoccio, M., Lu, Z., Ciucci, F., 2016. From material design to mechanism study: nano scale Ni exsolution on a highly active A-site deficient anode material for solid oxide fuel cells Nano Energy. 27, 499-508.

[7] Gao, Y., Wang, J., Lyu, Y.Q., Lam, K., Ciucci, F., 2017. In situ growth of $\mathrm{Pt}_{3} \mathrm{Ni}$ nanoparticles on an $\mathrm{A}$-site deficient perovskite with enhanced activity for the oxygen reduction reaction. J. Mater. Chem. A. 5(14), 6399-6404.

[8] Hui, J., Neagu, D., Miller, D.N., Yue, X., Ni, C., Irvine, J.T.S., 2018. Metal-oxide interactions for infiltrated Ni nanopartilces on A-site deficient $\mathrm{La}_{\mathrm{x}} \mathrm{Sr}_{1-3 \times 2} \mathrm{TiO}_{3}$. Solid State Ionics. 315,126-130.

[9] Kitla, A., Safonova, O.V., Fottinger, K., 2013. Infrared studies on bimetallic copper/nickel catalysts supported on zirconia and ceria/zirconia. Catal. Lett. 143(6), 517-530.

[10] Kwon, O., Joo, S., Choi, S., Sengodan, S., Kim, G., 2020. Review on exsolution and its driving forces in perovskite. J. Phys. Energy. 2(3), 032001 .

[11] Liu, S., Liu, Q., Luo, J.L., 2016a. Highly stable and efficient catalyst with in situ exsolved Fe-Ni alloy nanosphere socketed on oxygen deficient perovskite for direct $\mathrm{CO}_{2}$ electrolysis. ACS Cat. 6(9), 6219 6228

[12] Liu, S., Liu, Q., Luo, J.L., 2016b. $\mathrm{CO}_{2}$-to-CO conversion on layered perovskite with in situ exsolved Co-Fe alloy nanoparticles: an active and stable cathode for solid oxide electrolysis cells. J. Mater. Chem. A. $4(44), 17521-17528$.

[13] Lin, Y.C., 2013. Catalytic valorisation of glycerol to hydrogen and syngas. Int. J. Hydrogen Energy. 38(6), 2678-2700.

[14] Lindenthal, L., Rameshan, R., Summerer, H., Ruh. T., Popovic, J. Nenning, A., Loffler, S., Opitz, A.K., Blaha, P., Rameshan, C., 2020 Modifying surface structure of perovskite-based catalysts by nanoparticle exsolution. Catalyst. 10(3), 268.

[15] McIntosh, S., Gorte, R.J., 2004. Direct hydrocarbon solid oxide fuel cells. Chem. Rev. 104(10), 4845-4865. 
[16] Myung, J.H., Neagu, D., Miller, D.N., Irvine, J.T., 2016. Switching on electrolytic activity in solid oxide cells. Nature. 537(7621), 528-531.

[17] Neagu, D., Irvine, J.T., 2010. Structure and properties of $\mathrm{La}_{0.4} \mathrm{Sr}_{0.4} \mathrm{TiO}_{3}$ ceramics for use as anode Materials in solid oxide fuel cells. Chem. Mater. 22(17), 5042-5053.

[18] Neagu, D., Irvine, J.T., 2011. Enhancing electronic conductivity in Strontium Titanates through correlated A and B-site doping. Chem. Mater. 23(6), 1607-1617

[19] Neagu, D., Oh, T.S., Miller, D.N., Menard, H., Bukhari, S.M., Gamble, S.R., Gorte, R.J., Vohs, J.M., Irvine, J.T.S., 2015. Nano-socketed nickel particles with enhanced coking resistance grown in situ by redox exsolution. Nat. Commun. 6(1), 8120.

[20] Neagu, D., Papaioannou, E.I., Ramli, W.K., Miller, D.N., Murdoch, B.J., Menard, H., Umar, A., Barlow, A.J., Cumpson, P.J., Irvine, J.T., Metcalfe, I.S., 2017. Demonstration of chemistry through restructuring and catalytic activation at anchored nanoparticles. Nat. Commun. 8(1), $1-8$.

[21] Neagu, D., Tsekouras, G., Miller, D.N., Menard, H., Irvine, J.T., 2013. In situ growth of nanoparticles through control of non-stoichiometry. Nat. Chem. 5(11), 916-923.

[22] Nishihata, Y., Mizuki, J., Akao, T., Tanaka, H., Uenishi, M., Kimura, M., Okamoto, T., Hamada, N., 2002. Self-regeneration of a Pd-perovskite catalyst for automotive emissions control. Nature. 418(6894), 164-167.

[23] Papaioannou, E.I., Neagu, D., Ramli, W.K., Irvine, J.T., Metcalfe, I.S., (2019). Sulfur-tolerant exsolved Fe-Ni alloy nanoparticles for CO oxidation. Top. Catal. 62(17), 1149-1156.

[24] Perego, C., Villa, P., 1997. Catalyst preparation methods. Catal. Today. 34(3-4), 281-305

[25] Popovic, J., Lindenthal, L., Rameshan, R., Ruh, T., Nenning, A., Loffler, S., Opitz, A.K., Rameshan, C., 2020. High temperature water gas shift reaction reactivity of novel perovskite catalysts. Catalyst. 10(5), 582.

[26] Ramesh, S., Venkatesha, N.J., 2017. Template free synthesis of Niperovskite: an efficient catalyst for hydrogen production by steam reforming of bioglycerol. ACS Sust. Chem. Eng. 5(2), 1339-1346.

[27] Schwengber, C.A., Alves, H.J., Schaffner, R.A., da Silver, F.A., Sequinel, R., Bach, V.R., Ferracin, R.J., 2016. Overview of glycerol reforming for hydrogen production. Renew. Sust. Energy. Rev. 58, 259266.

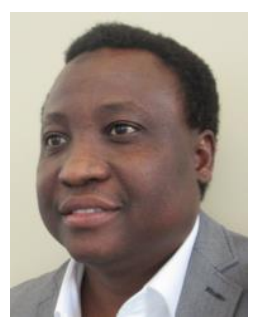

Dr. Ahmed Umar is a Senior Lecturer at the Department of Chemistry, University of Abuja, Nigeria. He received both his Bachelors and Master's degree in Applied Chemistry from Usmanu Danfodiyo University Sokoto, Nigeria. He obtained a $\mathrm{PhD}$ on design and development of solid materials for energy conversion from University of St Andrews, Scotland UK. His research interests are design, development and characterization of advanced functional materials for application in catalysis, biomass conversion to renewable energy, energy systems and environment.

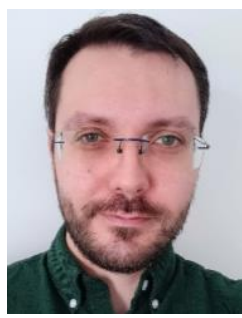

Dragos Neagu obtained his degree in chemical engineering from University Politehnica of Bucharest, Romania, in 2008. He received his $\mathrm{PhD}$ on materials and devices for electrochemical energy conversion from the University of St Andrews, UK in 2013. He then worked as a postdoctoral researcher at the University of St Andrews and Newcastle University. In 2020 he joined the University of Strathclyde as Lecturer in the Department of Chemical and Process Engineering. His research interests are in the design, preparation, multiscale characterization and application of nanostructured, functional materials for renewable energy conversion technologies.
[28] Sun, Y.F., Li, J.H., Zhang, Y.Q., Hua, B., Luo, J.L., 2016 Bifunctional catalyst of core-shell nanoparticles socketed on oxygendeficient layered perovskite for soot combustion: In situ observation of synergic dual active sites. ACS Catal. 6(4), 2710-2714.

[29] Tanaka, H., Uenishi, M., Taniguchi, M., Tan, I., Narita, K., Kimura M., Kaneko, K., Nishihata, Y., Mizuki, J., 2006. The intelligent catalyst having the self-regenerative function of $\mathrm{Pd}, \mathrm{Rh}$ and $\mathrm{Pt}$ for automotive emissions control. Catal. Today. 117(1-3), 321-328.

[30] Tao, S., Irvine, J.T., 2004a. Synthesis and characterization of $\left(\mathrm{La}_{0.75} \mathrm{Sr}_{0.25}\right) \mathrm{Cr}_{0.5} \mathrm{Mn}_{0.5} \mathrm{O}_{3-\delta}$, a redox-stable, efficient perovskite anode for SOFCs. J. Electrochem. Soc. 151(2), A252.

[31] Tao, S., Irvine, J.T., 2004b. Catalytic properties of the perovskite oxide $\mathrm{La}_{0.75} \mathrm{Sr}_{0.25} \mathrm{Cr}_{0.5} \mathrm{Fe}_{0.5} \mathrm{O}_{3-\delta}$ in relation to its potential as a solid oxide fuel cell anode material. Chem. Mater., 16(21), 4116-4121.

[32] Tsekouras, G., Neagu, D., Irvine, J.T. 2013. Step-Change in high temperature steam electrolysis performance of perovskite oxide cathodes with exsolution of B-site dopants. Energy Environ. Sci., 6(1), 256-266.

[33] Wei, H., Xie, K., Zhang, J., Zhang, Y., Zhang, Y., Wang, Y., Qin, Y. Cui, J., Yan, J., Wu, Y., 2014. In situ growth of $\mathrm{Ni}_{x} \mathrm{Cu}_{1-x}$ alloy nano catalyst on redox-reversible rutile $(\mathrm{Nb}, \mathrm{Ti}) \mathrm{O}_{4}$ towards hightemperature carbon dioxide electrolysis. Sci. Rep. 4(1), 5156

[34] Wu, G., Li, S., Zhang, C. Wang. T., Gong, J., 2014. Glycerol steam reforming over perovskite-derived nickel catalysts. Appl. Catal., B. 144, 277-285.

[35] Yasutake, T., Shinichi, N., Isamu, M., Shuichi, K., Kengo, S., Noboru, Y., 2000. Synthesis of manganite Perovskites by reverse homogeneous precipitation method in the presence of alkylammonium cation. Chem. Lett. 29(10), 1202-1203.

[36] Zhongpeng, W., Xiaomin, Z., Liguo, W., Zhaoliang, Z., Zheng, J. Tiancun, X., Ahmad, U., Qiang, W., 2013. Co-Mn-Al nonstoichiometric spinel-type catalyst derived from hydrotalcites for the simultaneous removal of soot and nitrogen oxides. Sci. Adv Mater. 5(10), 1449-1457.

[37] Zubenko, D., Singh, S., Rosen, B.A., 2017. Exsolution of Re-alloy catalysts with enhanced stability for methane dry reforming. Appl. Catal., B. 209, 711-719.

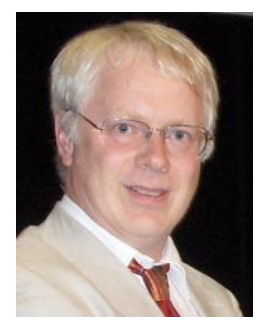

John Irvine, FRSE, FRSC, has made a unique and world-leading contribution to the science of energy materials, especially fuel cell and energy conversion technologies. This research has ranged from detailed fundamental to strategic and applied science and has had major impact across academia, industry and government. Irvine's science is highly interdisciplinary extending from Chemistry and Materials through physics, bioenergy, geoscience, engineering, economics and policy. The quality and impact of Irvine's research has been recognised by a number of national and international awards, including the Lord Kelvin Medal from the Royal Society of Edinburgh in 2018, the Schönbeim gold medal from the European Fuel Cell Forum in 2016, the RSC Sustainable Energy Award in 2015, with earlier RSC recognition via Materials Chemistry, Bacon and Beilby awards/medals. 